\title{
CRITERIOS DE ADMISIBILIDAD EN LA ACCIÓN DE INAPLICABILIDAD: A PROPÓSITO DE LA SENTENCIA DEL TRIBUNAL CONSTITUCIONAL ROL 2808-2015, DICTADA DENTRO DE LA DENOMINADA “ARISTA SOQUIMICH”*
}

\author{
Kamel CaZor Aliste**
}

\section{1) CRiterios de ADMisibilidad del aRTículo $84 \mathrm{~N}^{\circ} 6$ LOCTC}

Desde un comienzo -a tres años de la implementación de la inaplicabilidad- esta temática de la admisibilidad fue controvertida. En un trabajo de ese entonces ya se mencionaba que "muchos de los argumentos utilizados en sede de admisibilidad se pueden encontrar todavía en sentencias de fondo, generando entre los litigantes problemas de inseguridad sobre el alcance de los requisitos en estudio y, también, de desigualdad en el tratamiento de los requerimientos presentados" ${ }^{1}$. Especialmente clave es hacerse cargo del requisito de admisibilidad de la "fundamentación razonable", en el que suelen plantearse peticiones más bien centradas en la "mera legalidad" que en un conflicto de estricta "constitucionalidad". Lo que obligará a analizar, como primer asunto, las líneas jurisprudenciales que se han desarrollado sobre el particular, a fin de entender el contenido del concepto "razonablemente fundado", que paradójicamente no está definido ni en la Constitución ni en la Ley Orgánica.

Desde la Dirección de Estudios del Tribunal Constitucional, se ha puesto en marcha un intento para sistematizar los distintos criterios utilizados -emanados de las Salas del Tribunal- a la hora de declarar inadmisible una acción de inaplicabilidad por inconstitucionalidad (art. $93 \mathrm{~N}^{\circ}$ 6), diferenciando entre la etapa previa a la modificación de la Ley Orgánica Constitucional del Tribunal (en adelante también LOCTC) -en que no había causales de admisibilidad establecidas en ella-, y la posterior entrada en vigor de la Ley $\mathrm{N}^{\circ} 20.381$ de 2009 que modifica la LOCTC,

Parte de este comentario ya fue desarrollado en columna del Diario Constitucional titulada "La 'Arista Soquimich' y legitimidad del Tribunal Constitucional". Disponible en http:// www.diarioconstitucional.cl/articulos/la-arista-soquimich-y-legitimidad-del-tribunal-constitucional/

** Doctor en Derecho por la Universidad de Valladolid (España). Profesor Asociado de Derecho Constitucional en la Universidad Católica del Norte (ChILE). Correo electrónico: cazor@ucn.cl

1 Massmann Bozzolo, Nicolás (2009). "La admisibilidad del recurso de inaplicabilidad: a tres ańos de la reforma”. Revista Ius et Praxis, Vol. $15 \mathrm{~N}^{\circ} 1$, pp. 263-293. Disponible en : http://www.scielo.cl/scielo.php?script=sci_arttext\&pid=S0718-00122009000100008\&lng= es\&nrm=iso\&tlng=es [fecha de visita 15 de mayo de 2015] 
adaptándola a la nueva esfera atributiva que le entregó sobre inaplicabilidad la reforma de 2005. Respecto a las normas de la LOCTC se desarrollan por dicha Dirección de Estudios las causales de inadmisibilidad de los arts. 79, 80 y 84. Para los efectos de este comentario, solamente abordaremos la sistematización de la causal de inadmisibilidad del art. $84 \mathrm{~N}^{\circ}$ 6, esto es, "Cuando carezca de fundamento plausible"2.

La jurisprudencia del Tribunal Constitucional (en adelante también TC), sobre esta causal de inadmisibilidad, se puede sistematizar del siguiente modo:

- Falta de indicación sobre la forma precisa como la aplicación del precepto legal contraviene la Constitución.

- Falta de exposición circunstanciada de los hechos

- Cuestiones de mera legalidad que corresponden al juez de fondo (1). Sentido, alcance e interpretación legal: Señala el TC en la Sentencia Rol No 2465-20133: "Que la determinación del sentido y alcance del precepto impugnado en función del valor probatorio de los medios que obren en procesos seguidos ante jueces del fondo no es una materia propia de esta jurisdicción constitucional, dado que esto último importa igualmente una cuestión de legalidad cuya resolución es propia de los jueces de fondo. Se trata, por ende, de un conflicto que no se encuentra dentro del marco de atribuciones de este órgano de jurisdicción constitucional".

En este mismo sentido, encontramos los criterios de las siguientes sentencias: TC Rol No 2121, TC Rol N 1740, TC Rol N 1832, TC Rol N ${ }^{\circ}$ 2566, TC Rol N ${ }^{\circ}$ 1772, TC Rol N 1839, TC Rol No 2178, TC Rol No 2193, TC Rol No 2471, TC Rol No 1601, TC Rol N 1716, TC Rol N ${ }^{\circ} 1724$, TC Rol No 1853, TC Rol No 1860, TC Rol $N^{\circ}$ 1925, TC Rol No 2072, TC Rol No 2080, TC Rol No 2083, TC Rol N²084, TC Rol N²100, TC Rol N²107, TC Rol N 2184.

- Cuestiones de mera legalidad que corresponden al juez de fondo (2). Determinación de la ley aplicable en la gestión pendiente. Señala el TC en la Sentencia Rol No 1678-20104: "Que, en consecuencia, el conflicto cuya resolución se solicita a esta Magistratura no implica una cuestión de Constitucionalidad, en relación con el Art. 212 del C.C., que quede comprendida dentro de sus atribuciones (...) Sino, un asunto que debe ser resuelto por los jueces que conocen de la causa en que incide el requerimiento, los cuales han de determinar la forma de decidir la controversia sometida a su decisión".

2 Disponible en http://estudios.tribunalconstitucional.cl/leyorganica [fecha de visita 7 de octubre de 2015]

3 Disponible en http://www.tribunalconstitucional.cl/wp/ver.php?id=2804 [fecha de visita 14 de octubre de 2015]

4 Disponible en http://www.tribunalconstitucional.cl/wp/ver.php?id=1474 [fecha de visita 14 de octubre de 2015] 
En este mismo sentido, encontramos las siguientes sentencias: TC Rol N ${ }^{\circ} 1716$, TC Rol N 1925, TC Rol N² 2065, TC Rol No 2080, TC Rol No 2083, TC Rol No 2084, TC Rol N²151, TC Rol N ${ }^{\circ}$ 2176, TC Rol No 2210, TC Rol No 2318, TC Rol No 2553, TC Rol $\mathrm{N}^{\circ}$ 2566, TC Rol No 2617, TC Rol No 2239, TC Rol No 2418, TC Rol N ${ }^{\circ} 2150$, TC Rol No 1466, TC Rol N² 2031, TC Rol No 2451, TC Rol No 2461, TC Rol No 2808, TC Rol No 2815, TC Rol N ${ }^{\circ}$ 2861, TC Rol No 2863.

- Revisión de resoluciones judiciales.

- Impugnaciones a sistemas normativos completos.

- Error formal de referencia normativa.

- Nuevo requerimiento dentro de la misma gestión pendiente.

- Reproche contra los efectos jurídicos de la aplicación del precepto impugnado.

- El precepto legal sirve de fundamento y favorece al requirente en la gestión pendiente.

- Impugnación es más amplia de aquella estampada en el requerimiento.

- Carácter abstracto de reproche constitucional.

- Cuestión planteada contradice pronunciamientos recientes de esta Magistratura. En la sentencia del TC Rol No $1740-2010^{5}$, se indica: "Para que la inaplicabilidad pueda prosperar, debe estarse siempre en presencia de un conflicto de constitucionalidad, esto es, frente a una contradicción directa, clara y precisa entre determinado precepto legal que se pretende aplicar en el caso concreto, con la propia Constitución". Luego en las sentencias TC Rol No 2430-2013 ${ }^{6}$ y TC Rol No 2512-2013 señala: "Sin embargo, de las argumentaciones vertidas es posible advertir que lo planteado entra en contradicción con pronunciamientos recientes de esta Magistratura, que han declarado la conformidad con la Constitución de la misma norma legal objetada en este requerimiento, sin que se advierta un cambio efectivo de las circunstancias que llevaron a fallar en dicho sentido".

- Existencia de precepto legal aplicable que no ha sido impugnado.

- Actor pretende aplicación de precepto legal conforme a su texto modificado.

- Fundamentos de hecho fuera de los casos y formas a que se refiere el precepto legal objetado.

- Impugnación de un acto administrativo.

5 Disponible en http://www.tribunalconstitucional.cl/wp/ver.php?id=1402 [fecha de visita 14 octubre 2015]

6 Disponible en http://www.tribunalconstitucional.cl/wp/ver.php?id=2853 [fecha de visita 14 octubre 2015]

Disponible en http://www.tribunalconstitucional.cl/wp/ver.php?id=2890 [fecha de visita 14 octubre 2015] 
- Acción interpuesta pretende alterar la institución desarrollada en la disposición objetada.

- Requerimiento con argumentaciones contradictorias e insuficientes.

- Se objeta el mérito de los preceptos.

- Se impugna precepto legal respecto de más de una gestión.

- Precepto legal impugnado no tendrá el efecto que le atribuye el requirente en la gestión pendiente.

- Requirente dispone de medios legales para impugnar actuaciones judiciales.

Finalmente hay que indicar, que desde el año 2006, al examinar este requisito, el Tribunal Constitucional homologó las expresiones "fundamento plausible" con "razonablemente fundado", utilizándolos indistintamente en los considerandos de los fallos de admisibilidad. Luego, en el ańo 2009, al revisar el TC la constitucionalidad de la LOCTC, por vía de control preventivo obligatorio, declaró la constitucionalidad del requisito "fundamento plausible", en el entendido de que este se homologa al requisito contenido en el art. 93, inciso $11^{\circ}$, de la Constitución, que señala que la impugnación estar "razonablemente fundada". En este sentido el TC en sentencias Rol No 2090-20118 y Rol N ${ }^{\circ} 2094-2011^{9}$ ha señalado: "Esta Magistratura ha entendido como fundamento razonable la exigencia de contener una exposición clara, detallada y especifica de los hechos y fundamentos de que se apoya el requerimiento, lo que significa que el requirente debe expresarse de tal manera que sean inteligibles, los hechos del caso concreto, la forma en que la aplicación del precepto impugnado contraviene la Constitución, y la norma constitucional vulnerada".

\section{2) PROBLEMATIZACIÓN DEL ANÁlisis JURISPRUDENCIAL DE INADMISIBILIDAD A PROPÓSITO DE LA DENOMINADA “ARISTA SOQUIMICH”}

En los últimos meses hemos sido testigos de varios sucesos delictivos que han afectado profundamente la estructura básica de nuestro Estado constitucional y democrático de Derecho: el "Caso Penta" y la denominada "Arista Soquimich". Repercutiendo en uno de los principales actores y elemento consustancial de todo Estado democrático: los partidos políticos; comprendiéndose en este caso todo el espectro partidista chileno, tanto el oficialismo (Nueva Mayoría) como la oposición (Alianza

8 Disponible en http://www.tribunalconstitucional.cl/wp/ver.php?id=2193 [fecha de visita 14 octubre 2015]

9 Disponible en http://www.tribunalconstitucional.cl/wp/ver.php?id=2207 [fecha de visita 14 octubre 2015] 
o, actualmente, Chile Vamos), y los otros partidos o movimientos extraparlamentarios. Como bien es sabido, todo ello ha profundizado en el persistente desprestigio en la ciudadanía de las instituciones estatales, en general, y de la clase política, en particular.

Ahora bien y en lo que nos interesa, uno de los ángulos del "Caso Penta", la "Arista Soquimich" (como gestión pendiente ante el $8^{\circ}$ Juzgado de Garantía), llegó al Tribunal Constitucional (Rol No 2808-201510), a través de una acción de inaplicabilidad presentada por el ex ejecutivo de Soquimich Patricio Contesse González impugnando los artículos 180, 205, 212 y 217, inciso segundo, del Código Procesal Penal, por estimar que se infringían las siguientes normas constitucionales: arts. $19 \mathrm{n}^{\circ} 2,19$ $\mathrm{n}^{\circ} 3$, incisos primero y sexto, art. $19 \mathrm{n}^{\circ} 7$, letra f), y arts. $6^{\circ}$ y $7^{\circ}$. En el requerimiento se indicaba que el Ministerio Público, sin habilitación legal, pretendía hacerse de antecedentes en oficinas de su representada (Soquimich, de la cual, dicho sea de paso, no invocó ni acreditó representación). Igualmente se señalaba, que los antecedentes que se pretendían por el Ministerio Público, nada tenían que ver con la querella interpuesta por el Servicio de Impuestos Internos.

El requerimiento ingresó al Tribunal Constitucional el día 16 de marzo de 2015, resolviéndose al día siguiente su admisión a trámite. Lo particular y controvertido de esta sentencia de 17 de marzo -resuelta por decisión unánime-, fue su extrema prontitud y que además suspendió el procedimiento, "solamente respecto de audiencias, actuaciones, resoluciones y autorizaciones que se refieren a medidas intrusivas en la denominada, por el requirente, "arista soquimich" de la gestión invocada"; y luego el Tribunal decretó oír alegatos de admisibilidad. Con ello, de un día para otro, nuestro Tribunal Constitucional se vio "involucrado" en este contingente caso político-judicial, y, de paso, fue foco -como pocas veces ha ocurrido- de la atención de la prensa y de la opinión pública nacional (recuérdese también el caso "Píldora II" Rol N 740-2007). Posteriormente, al resolver la admisibilidad con fecha 25 de marzo -por decisión igualmente unánime-, estima el Tribunal que "se desprende que lo planteado en el requerimiento es una cuestión de armonización e interpretación de distintas normas de rango legal, propia de la órbita de los jueces de fondo, y no una cuestión de constitucionalidad de aquellas que deba resolver este Tribunal (Considerando $\left.4^{\circ}\right)$... el libelo de fojas 1 carece de fundamento plausible, por implicar la formulación de un conflicto de interpretación de las normas que regulan la actividad del Servicio de Impuestos Internos y del Ministerio Público, a propósito del ejercicio de la acción penal y la función investigativa, cuestión que excede

10 Disponible en http://www.tribunalconstitucional.cl/wp/ver.php?id=3096 [fecha de visita 7 de abril de 2015] 
los términos de un requerimiento de inaplicabilidad por inconstitucionalidad" (Considerando 5\%).

La pregunta que surge por sí sola es la siguiente: ¿en estas dos etapas de control de forma, el razonamiento jurisdiccional de la Segunda Sala del Tribunal Constitucional fue suficientemente fundado y coherente? A mi parecer no. Las razones de esta conclusión son dos: Por una parte, careció de una fundamentación integral del asunto sometido a su conocimiento, aislando dos trámites de verificación de forma, que están necesariamente conectados (como es la admisión a trámite y el juicio de admisibilidad). Y, por otra, le faltó coherencia al momento de ponderar los antecedentes (jurídicos y fácticos) y con ello llegar a la decisión de suspender el procedimiento, especialmente teniendo en cuenta los estándares de racionalidad que es deber exigir a un Tribunal de esta jerarquía; "orden de no innovar" que cuesta mucho racionalizar, especialmente, a la luz de su decisión posterior que acoge unánimemente la inadmisibilidad de la acción.

Si contrastamos la decisión en comento con otra cuestión que también resolvió el Tribunal Constitucional coetáneamente -pero en su Primera Sala-, denominado "Fraude al FUT" (Rol No 2768-201511), podemos observar que la respuesta jurisdiccional no fue la misma desde el punto de vista de la prontitud y las medidas que se tomaron. En este caso, la sentencia que declaró la inadmisibilidad en definitiva, se pronunció habiendo transcurrido, más o menos, 60 días desde que se presentó el requerimiento; frente a los solo 9 días que tardó en resolverse la inadmisibilidad en la "Arista Soquimich". Además, en el primer caso no se suspendió el procedimiento, frente a la suspensión que sí se decretó en el segundo proceso; no obstante que ambas sentencias, que declararon las respectivas inadmisibilidades, se basaron en presupuestos con muy cercanas similitudes y fundados en idénticas causales de rechazo (art. 84, $\mathrm{N}^{\circ} 5$ y 6, LOCTC).

Retomando lo que ya se adelantó con anterioridad, el Tribunal, al admitir a trámite el requerimiento, careció de una fundamentación integral del asunto sometido a su conocimiento, pues aisló dos trámites que están necesariamente conectados, como es la "admisión a trámite" y el "juicio de admisibilidad", contradiciendo de paso su anterior jurisprudencia en este tema. En efecto, si se analizan algunos fallos de la misma Segunda Sala, encontramos una clara línea jurisprudencial (período 2012-2015), en la cual el Tribunal ha ratificado como criterio jurisprudencial la inutilidad de pronunciarse en torno a la admisión a trámite, cuando es manifiesto que el requerimiento adolece de un vicio de inadmisibilidad (en particular cuando "carezca de fundamento plausible", lo que se traduce en no

11 Disponible en http://www.tribunalconstitucional.cl/wp/ver.php?id=3095 [fecha de visita 7 de abril de 2015] 
expresar el conflicto de constitucionalidad), es decir, en estas circunstancias derechamente lo declara inadmisible, al carecer de toda relevancia la decisión sobre la admisión a trámite.

A fin de ilustrar esta aseveración, citaré los considerando más pertinentes de algunas sentencias del Tribunal Constitucional:

A) Causa Rol No 2349-201212: "7". Que de la sola lectura del libelo de fojas 1 se desprende que no se expone cuál es el conflicto de constitucionalidad planteado, ya que no se contiene una exposición clara, detallada ni especifica de los hechos y fundamentos en que se apoya. Por otra parte, no se argumenta cómo la aplicación de los preceptos impugnados produciría, en el caso concreto que se invoca, el resultado de infracción constitucional que se denuncia, motivo por el cual resulta imposible estimar cumplidos los presupuestos establecidos por el legislador -ya transcritos- para acoger a trámite la acción y declararla admisible; $8^{\circ}$. Que, para que se entienda satisfecha la exigencia constitucional de encontrarse razonablemente fundada la acción, el requerimiento que se intente ante esta Magistratura no solo debe señalar con precisión y suficiente detalle los hechos de la causa sub lite y también indicar cuáles son los preceptos constitucionales que podrian verse violentados de ser aplicada la o las determinadas normas legales impugnadas en el proceso judicial pendiente ante un tribunal ordinario o especial en el que sea parte el actor, sino que, además, debe señalarse de manera clara, delimitada y específica, la forma en que se podría producir la contradicción constitucional en el asunto concreto que se discute en el mismo proceso judicial. En efecto, esta Magistratura ha sostenido que la exigencia constitucional de fundamentar razonablemente un requerimiento de inaplicabilidad, para los efectos de declarar su admisibilidad, supone una "condición que implica-como exigencia básica- la aptitud del o de los preceptos legales objetados para contrariar, en su aplicación al caso concreto, la Constitución, lo que debe ser expuesto circunstanciadamente. La explicación de la forma en que se produce la contradicción entre las normas, sustentada adecuada y lógicamente, constituye la base indispensable de la acción ejercitada." (Sentencias roles $N^{\circ}$ s 482, 483, 484, 485, 490, 491, 492, 494, 1772 y 2121, entre otras)".

B) Causa Rol No 2490-201313: "5. Que esta Magistratura Constitucional, en oportunidades anteriores y atendido el mérito de cada caso particular, ha determinado que el requerimiento de inaplicabilidad interpuesto adolece de vicios o defectos tales que hacen imposible que pueda prosperar, siendo, así, impertinente que la Sala respectiva efectúe un examen previo de admisión a trámite y procediendo que la misma declare derechamente la inadmisibilidad de la acción deducida; $6^{\circ}$. Que, atendido el mérito de los antecedentes

\footnotetext{
12 Disponible en http://www.tribunalconstitucional.cl/wp/ver.php?id=2615 [fecha de visita 7 de abril de 2015]

13 Disponible en http://www.tribunalconstitucional.cl/wp/ver.php?id=2895 [fecha de visita 7 de abril de 2015]
} 
que obran en autos, esta Sala ha logrado convicción en cuanto a que la acción constitucional deducida no puede prosperar, toda vez que no cumple con las exigencias constitucionales y legales antes transcritas, al no concurrir el presupuesto de estar razonablemente fundado el libelo de fojas 1, configurándose, en la especie, la causal de inadmisibilidad del número $6^{\circ}$ del ya transcrito artículo 84 de la Ley $N^{\circ}$ 17.997, sin perjuicio de la eventual concurrencia de otras causales de inadmisibilidad. En efecto, en el libelo de fojas 1 no se plantea un conflicto de constitucionalidad, sino que una cuestión de mera legalidad, en la medida que el requerimiento se sustenta en la determinación de la competencia del $2^{\circ}$ Juzgado Militar de Santiago y en el sentido y eficacia en el tiempo de la Ley $N^{\circ}$ 20.477, que modificó la competencia de los tribunales militares".

C) Causa Rol No 2765-201514: "7. Que esta Magistratura Constitucional, en oportunidades anteriores y atendido el mérito de cada caso particular, ha determinado que si un requerimiento de inaplicabilidad, como el interpuesto en la especie, adolece de vicios o defectos tales que hacen imposible que pueda prosperar, resulta impertinente que la Sala respectiva efectúe un examen previo de admisión a trámite a su respecto y procede que la misma declare derechamente la inadmisibilidad de la acción deducida (entre otras, sentencias roles $N^{\circ}$ s 1890, 1878, 1860, 1789, 1834, 1828, 1788, 1771, 1749, 1878, 1935, 2088, 2124, 2353, 2361, 2476, 2662 y 2686, entre otros)".

\section{3) COMENTARIO FINAL}

En resumidas cuentas, es posible deducir que en la denominada "Arista Soquimich", resultaba evidente la inexistencia de un conflicto de constitucionalidad, pues era manifiesto que la acción carecía de "fundamento plausible", y que, además, esta pudiere prosperar. En consecuencia, de acuerdo a las prácticas jurisprudenciales del propio Tribunal, debió haber sido declarado inadmisible de entrada, y, a mayor abundamiento, al plantearse en el requerimiento un conflicto de normas del Código Tributario y del Código Procesal Penal, era evidente que no debía acogerse a tramitación pues solo existía un vicio de ilegalidad, incumpliéndose lo prescrito en los arts. 80 y $84 \mathrm{~N}^{\circ} 6$ de la LOCTC. Basta leer el requerimiento para darse cuenta de ello, cuestión que luego ratificó en sus considerando $\left(4^{\circ}\right.$ y $\left.5^{\circ}\right)$ el propio Tribunal al declarar la inadmisibilidad. Todo ello nos hace necesariamente concluir, lo altamente cuestionable de la actuación de la Segunda Sala del Tribunal Constitucional en este caso, pues

14 Disponible en http://www.tribunalconstitucional.cl/wp/ver.php?id=3076 [fecha de visita 7 de abril de 2015] 
claramente se alejó del cometido que le encarga la Carta fundamental y su Ley Orgánica, saliéndose de los contornos de una actuación estrictamente jurisdiccional, y entrando de lleno en la arena -que sin lugar a dudas le está vedada- de la contingencia político-judicial, que, como bien es sabido, tanto descrédito le está ocasionando al sistema institucional chileno. $L a-$ mentablemente - a mi juicio- la legitimidad del Tribunal Constitucional en su conjunto se ha visto seriamente afectada en este caso; ya que, cabe recordar, dicha legitimidad arranca de su propia esfera atributivo-competencial, que en este asunto no se respetó rigurosamente. Como tampoco se acató la doctrina jurisprudencial que la propia Segunda Sala del Tribunal había venido desarrollando en los últimos años, a propósito de esta verificación de forma en sede de inaplicabilidad. 